\title{
Analysis of the equipment and instrumentation qualification criteria using 3D containment models
}

\author{
Gonzalo Jimenez , Mikel Kevin Fernández-Cosials, Rafael Bocanegra, César Queral \\ Universidad Politécnica de Madrid, c/ J osé Gutiérrez Abascal, 2, 28006 Madrid, Spain
}

\begin{abstract}
A B S T R A C T

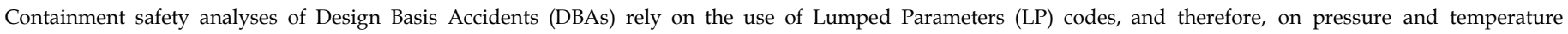

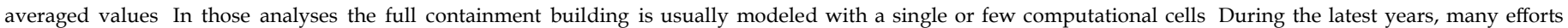

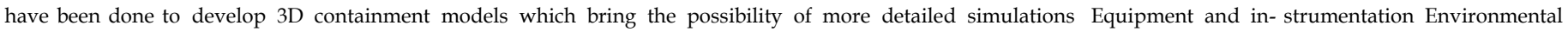

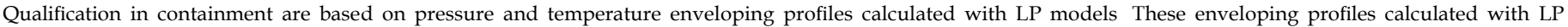

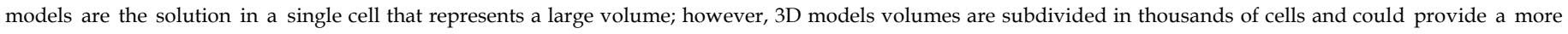

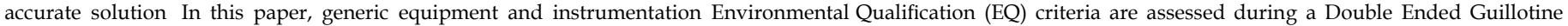
Break Loss Of Coolant Accident in a PWR-W 3D containment model developed with GOTHIC 81 (QA)
\end{abstract}

\section{K E Y W O R D S}

Environmental Qualification

Containment

GOTHIC

PWR

Safety analysis

DBA

\section{Introduction}

In the licensing process of a Nuclear Power Plant (NPP), the Deterministic Safety Analysis (DSA) is used to qualify the design against transients and accidents. For PWR containment safety analysis, the Loss of Coolant Accident (LOCA) and the Main Steam Line Break (MSLB) accidents, commonly grouped in High Energy Line Breaks (HELBs) are normally chosen as the transients which maximize the Mass and Energy (M \& E) release to the containment atmosphere from the primary and secondary cooling system, (Tills et al., 2009). This maximized release is assumed to create the most conservative conditions in the containment, regarding pressure and temperature, (Sehgal, 2012).

To conduct those containment safety analyses and evaluate the consequences of an accident in the containment atmosphere, some challenges are faced. First, the need to model a containment with a large free volume (around $60,000 \mathrm{~m}^{3}$ ) and a complex geometry. Second, the small characteristic length scale of the simulation phenomena, such as friction, conduction, convection and condensation.

How to deal with those different length scales? The solution traditionally taken is the Lumped Parameters (LP) approach, which uses correlations to simulate the physical phenomena and models the con tainment in a single or few computational cells. Therefore, it is possible to model a large building such a NPP containment and, at the same time, capture the friction, conduction, convection and condensation phenomena. The LP approach provides reasonable results on pressure and temperature with very low computational requirements. Regulatory bodies have accepted the LP approach, imposing some biases. Examples of NPP containment analyses with this approach can be found in Abdelghany et al. (2004), Dominion (2006), Duke Power Company (2004), Ofstun (2004, 2001), WEC (2004, 2013). However, the LP approach has assumptions such as instantaneous fluid mixing inside a control volume, no 2D/3D effects of the flow patterns, in stantaneous interaction of all thermal structures with the fluid inside a control volume and no forced convection. It is mentionable that some of these hypothesis have been questioned historically, see for example (Whitley et al., 1976; Corradini, 1984). As a summary, although its limitations, containment Design Basis Accident (DBA) analysis per formed with the LP approach can lead to obtain the global pressure and temperature limits in a NPP containment.

The pressure obtained in these containment analyses was historically taken into account to set design parameters such as the minimum free volume inside the containment, or the thickness of the containment walls among other design criteria, see 10 CFR 50 Ap. A Criterion 50, (NRC, 2015). The temperatures evolution obtained with these analyses are also taken into account for several design criteria. Specifically, it is used to create an enveloping temperature profile that covers all Design Basis Events (DBE) used for the Environmental Qualification (EQ) of equipment and instrumentation important to safety inside the con tainment, (EPRI, 2010). This equipment is tested and subjected to the enveloping temperature profile to assure its performance under DBE

* Corresponding author

E-mail addresses: gonzalo jimenez@upm es, gonzalojimenezvaras@yahoo es (G Jimenez) 
conditions.

As knowledge and computer resources increase, new software tools are developed and new levels of accuracy and detail can be achieved. This kind of improvement was implemented many years ago in order to perform realistic estimations of the fuel and the Emergency Core Cooling System (ECCS) performance during LOCA sequences (NRC, 1988). However, although the new 3D capabilities of containment codes such as GOTHIC or GASFLOW are available (EPRI, 2014a; Travis et al., 2011), containment safety analyses, and then EQ enveloping profiles, are still done nowadays using the LP approach.

With an adequate cell size in a 3D containment model, flow patterns and physical variables can be tracked and analyzed with an accuracy level unreachable for LP models. International organisms are taking into account these new tools, although not for DBA analysis, (OECD/ NEA, 2014a,b). The first use of these 3D models was motivated by hydrogen distribution analysis and then evolved to containment severe accident analysis thermal hydraulics, see (Wolf et al., 1999; Royl et al., 2000; Kim et al., 2004; Martín Valdepeñas et al., 2007) or (Jimenez et al., 2015). IAEA and the OECD/NEA state that CFD codes are able to reproduce more accurately the thermal hydraulic containment phe nomenology involving hydrogen (Abou Rjeily et al., 2011; OECD/NEA, 2014c).

Recently, in the UPM Nuclear Safety Group, GOTHIC 3D models have been created and tested to simulate and analyze a Large Break LOCA, and a comparison between LP and 3D models, see (Bocanegra et al., 2016 and Jiménez et al., 2014). The DBA analysis compares the simulation results against the safety limits of pressure and temperature for containment. During a transient, the pressure is transmitted at sonic speed all over the rooms, and it became homogeneous almost instantly in the full containment, so there is not a noticeable difference between LP and 3D models results. However, temperature distribution is more heterogeneous, as slower convective diffusive processes are responsible for its spreading. 3D flow patterns inside the containment affect directly to this temperature spreading. Therefore, achieving a sufficiently ac curate nodalization is crucial to correctly predict these flow patterns. With a LP model, it is not possible to observe all these phenomena. 3D models are able to capture these phenomena and therefore analyze new parameters such as room maximum local temperature, three dimen sional flow patterns or heat flux through specific equipment or con tainment walls. This fact impulses the need of an analysis on the tem perature limits obtained by a LP model, as it is based on global average values.

In this paper, an analysis of the temperature limits obtained from LP models is firstly faced. Secondly, the PWR W containment 3D model and the M\&E release inputs used are described. Thirdly, the LOCA simulations presented are analyzed under the terms of the temperature limits previously mentioned. Finally, discussion and conclusions are drawn. All simulations have been performed using the GOTHIC 8.1 (QA) code.

\section{Environmental qualification and 3D containment models}

In this section, a small depiction of EQ within containments is made along with a comparison of the peak values of the enveloping profiles used for different NPPs.

EQ requirements from NRC have passed through from the DOR Guidelines and NUREG 0588 to the EQ Final Rule as 10 CFR 50.49, which started to apply in 1983, (NRC, 1983). In this regulation, a DBE is defined as any event that produces a harsh environment, this is, dif ferent from the normal or abnormal conditions. Moreover, in a NPP, all safety related equipment, directly or indirectly, that requires harsh environment qualification is grouped into the Environmental Qualifi cation Master List (EQML). The performance requirements of an EQML
Table 1

Different containment maximum temperatures in the enveloping profile for environmental qualification.

\begin{tabular}{lll}
\hline Maximum temperature & Country/NPP & Reference \\
\hline $160{ }^{\circ} \mathrm{C}$ & Belgium/DOEL & European Commission (1996) \\
$155^{\circ} \mathrm{C}$ & Finland/Loviisa & European Commission (1996) \\
$172{ }^{\circ} \mathrm{C}$ & Spain & European Commission (1996) \\
$170{ }^{\circ} \mathrm{C}$ & Sweden & European Commission (1996) \\
$200{ }^{\circ} \mathrm{C}$ & UK & European Commission (1996) \\
$190^{\circ} \mathrm{C}$ & Korea & Hyun et al. (2006) \\
$260^{\circ} \mathrm{C}$ & AP1000 & Clark and Fröding (2014) \\
$130^{\circ} \mathrm{C}$ & Krsko/Slovenia & Cavlina et al. (1996) \\
$177^{\circ} \mathrm{C}$ & US-APWR & MHI (2013) \\
\hline
\end{tabular}

component are tested regarding their location, qualification criteria or harsh DBA among others.

The harsh environment is calculated by a thermal hydraulic code including several assumptions to maximize containment temperature and pressure. NUREG 0588 identifies several computer codes accep table for defining these conditions, (NRC, 1981). Different HELB, pro vide different pressure and temperature profiles, and it is common practice to create an envelope of all calculated profiles. Then, equip ment qualified with an enveloping profile is considered acceptable for any plant specific or location specific profile that falls within the en velope, (EPRI, 2010). It is remarkable that different containment zones can be evaluated separately, as seen in (EPRI, 2010), however, these different zones are modeled as LP volumes.

Generic industry environmental profiles have been available, see (IEEE, 1974; NRC, 1981). However, these generic profiles are actually of discouraged use; NPP and countries regulatory bodies should cal culate their own plant specific profiles as stated in the Regulatory Guide 1.89 (NRC, 1984), or in the latest IEEE for 1E equipment, (IEEE, 2003) and its revision (IEEE, 2016). Therefore, the peak temperature of the EQ enveloping profile is country and/or plant specific, as shown in Table 1 (they are not up to date values, and each country value may be subordinated to the plant specific ones). In addition, IEEE establishes a margin of $8{ }^{\circ} \mathrm{C}$ to these safety limits (IEEE, 2003).

Instrumentation in a PWR W containment has to bear accident conditions similarly to an EQML component. NPPs are encouraged to use plant specific values, (Basic, 2015) but generic values are also available. Generic values for peak temperatures are set to $148{ }^{\circ} \mathrm{C}$, see (Arcieri and Hanson, 1991; Hashemian, 2006). Recent studies like (Knudson et al., 2015) have used this limit to assess an accident with the MELCOR code, using a containment model with nine control vo lumes. It is stated that the instrument performance will be degraded if pressure and temperature environments exceeds these instrumentation EQ (Environmental Qualification) ranges, and that instrument perfor mance is not well known if those limits are exceeded (King et al., 1988).

In this paper the general criteria used for qualifying containment equipment and instrumentation are used to assess but with a $3 \mathrm{D}$ com putational model instead of a LP model. The temperature that affects an electrical or mechanical equipment, or the instrumentation in con tainment is the temperature of its nearby surroundings and unlike LP models, this local temperature can be calculated using 3D models.

To address this issue and expose differences, as a first step, a 3D containment model is made with all rooms located and labeled in dependently. It will be taken as a hypothesis that all rooms of the containment could contain electrical equipment (cables, pumps, etc.) or instrumentation. Secondly, the detailed room conditions under a DBA will be extracted from the 3D simulations performed with GOTHIC. Thirdly, the peak temperature of the enveloping profile will be the variable to assess, given that if it is surpassed anytime, the EQ criteria 


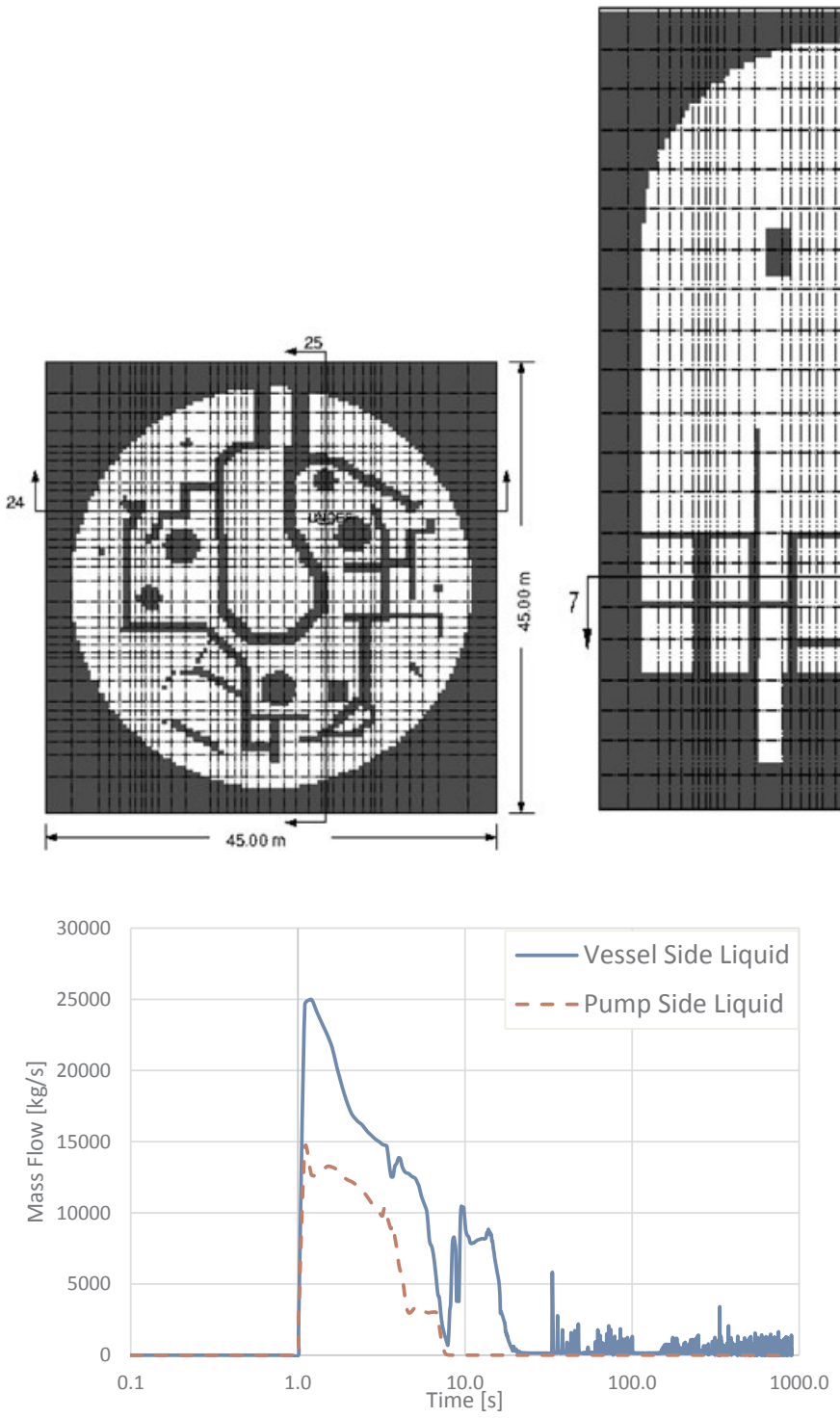

Fig. 2. Liquid mass flow of the $M \& E$ release (base case).

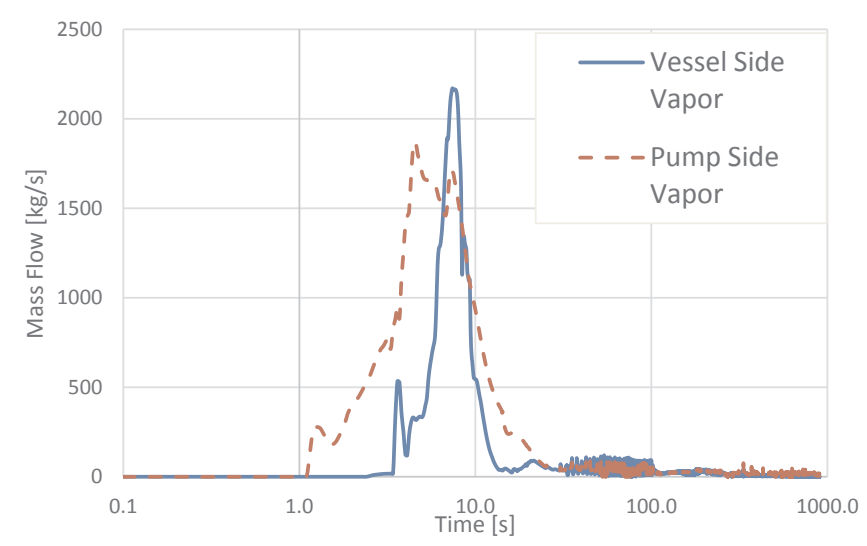

Fig. 3. Vapor mass flow of the M \& E release (base case).

will be surely surpassed. In this aspect, the peak temperature criterion for equipment and instrumentation will be set to $148.9^{\circ} \mathrm{C}$, as it has been the general criteria used for decades (IEEE, 1974); if this local condi tions are exceed, it would be considered that equipment and in strumentation in this room is under damage conditions. This damage

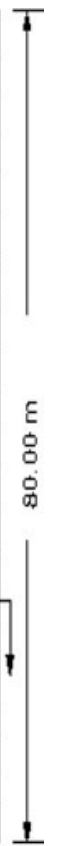

Fig. 1. PWR-W GOTHIC 3D model.

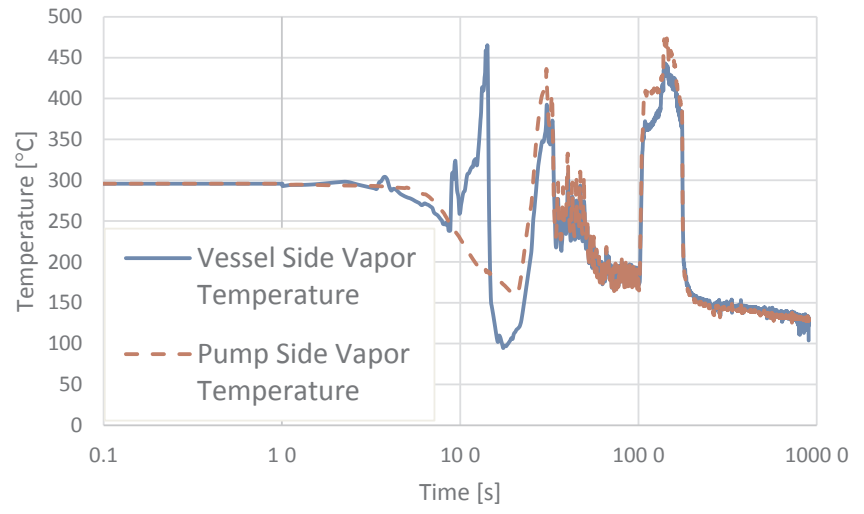

Fig. 4. Vapor temperature of the $M \& E$ release (base case).

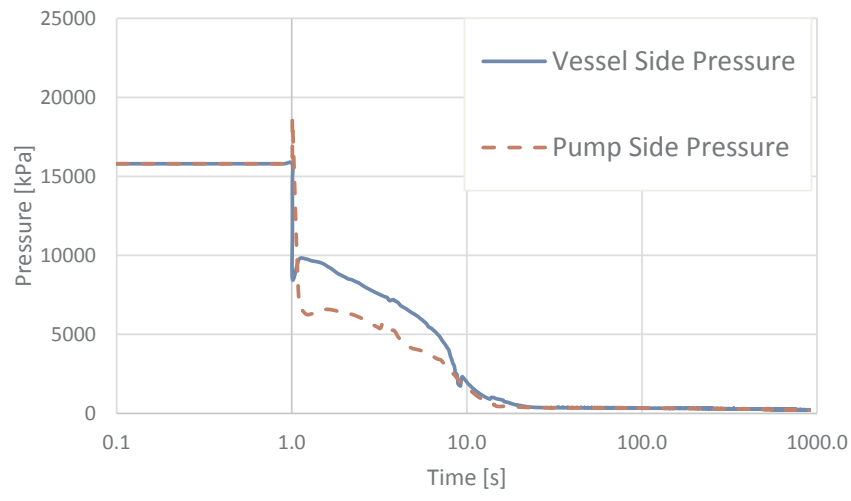

Fig. 5. Pressure of the M \& E release (base case).

will be quantified by the room peak temperature and pressure, and the amount of time that a cell or group of cells inside this room are ex ceeding the limits for a generic PWR W. This criterion will be applied in the next sections of the paper to a DBE DEGB LOCA for a PWR W containment for demonstration purposes. 


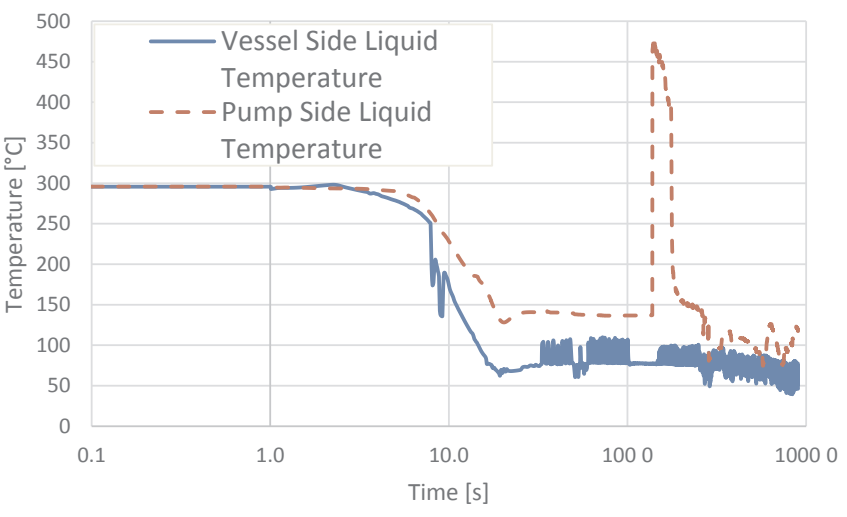

Fig. 6. Liquid temperature of the $M \& E$ release (base case).

\section{Average Temperature in Containment}

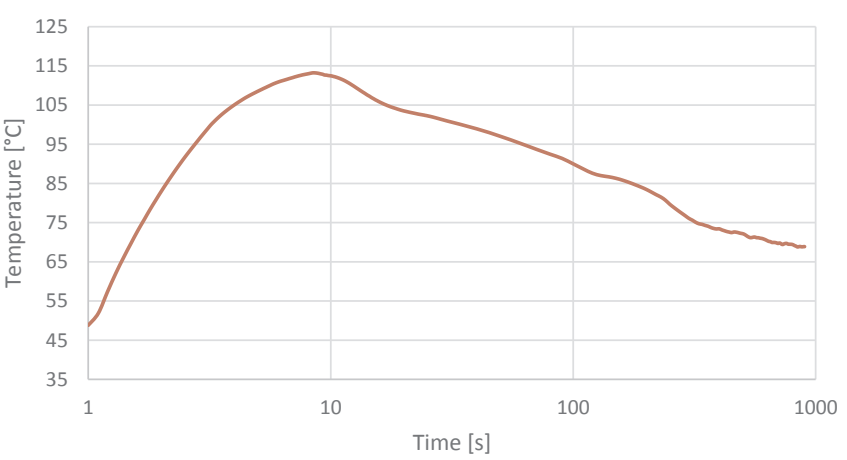

Fig. 7. Average containment temperature evolution (base case).

\section{Average Pressure in Containment}

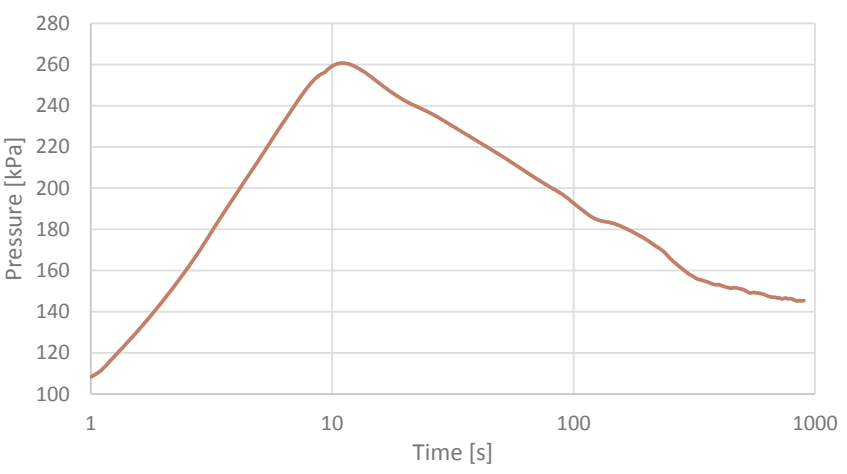

Fig. 8. Average containment pressure evolution (base case).

Average Room Temperature

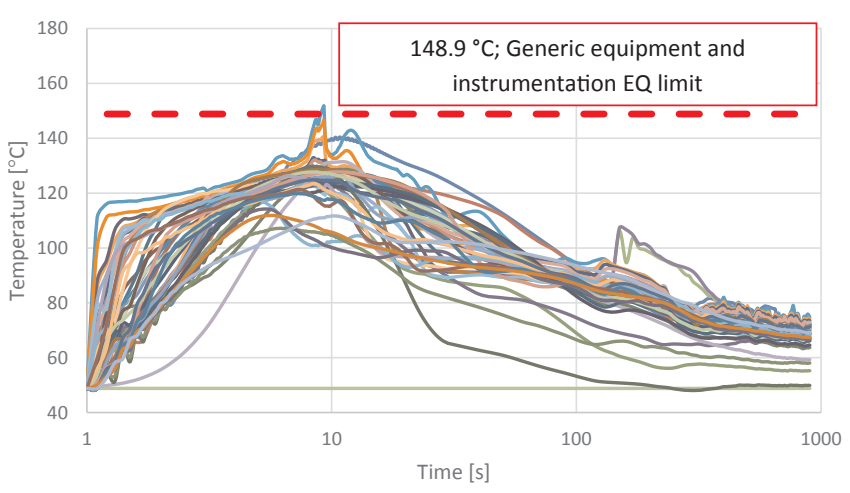

Fig. 9. Room average temperature evolution (base case).

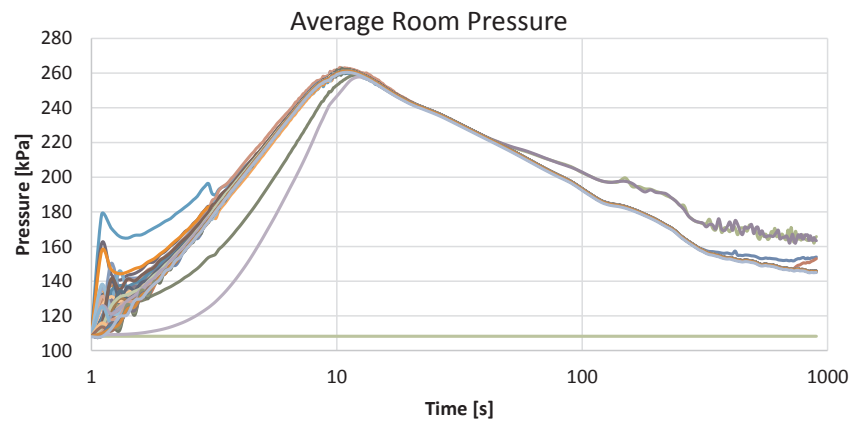

Fig. 10. Room average pressure evolution (base case).

\section{PWR-W containment model and $M \& E$ release input}

\subsection{The GOTHIC code}

GOTHIC 8.1 (QA), (EPRI, 2014b), is an integrated, general purpose thermal hydraulics software package for design, licensing, safety and operating analysis of nuclear power plant containments, confinement buildings and system components.

GOTHIC can solve the conservation equations for mass, momentum and energy for multi component, multi phase flow for three fields: gas mixture, continuous liquid and droplets. A finite volume method is used, and cell volume and surface porosities are used to model complex geometries. It also includes full treatment of the momentum transport terms in multi dimensional models, with optional models for turbulent shear and turbulent mass and energy diffusion. In contrast to standard CFD codes, GOTHIC does not have a body fitted mesh capability. GOTHIC code uses empirical 1D correlations for friction and the heat transfer between the fluid and the structures rather than attempting to model the convection specifically. The subdivision of a volume into a multi dimensional grid is mandatory in orthogonal coordinates

The 3 D capabilities of GOTHIC in simulating basic flows, and basic phenomena (mainly for hydrogen) for containment analysis have been investigated extensively simulating test in facilities like PANDA, CSTF, BFMC or CVTR (Andreani et al., 2010; Paladino et al., 2010; Fernández Cosials et al., 2016).

\subsection{GOTHIC $3 D$ model}

The containment structure of a PWR W must be able to withstand a pressure peak of approximately 5.5 bars, to deal with the most severe postulated accidents during the plant life time (Hessheimer and Dameron, 2006). One of the typical PWR containment configuration consists in a cylinder with a hemispherical dome with an external concrete barrier and an internal steel liner. This PWR containment modeled with the GOTHIC code is based on a 3 Loop PWR W config uration.

A summarized model description is explained below. In addition, detailed information about it can be found in (Bocanegra et al., 2016) and the construction process (Jiménez et al., 2014). The detailed geo metrical model of the containment is firstly created with a CAD soft ware. Then a simplified CAD model using only the geometries GOTHIC allows is created. Thirdly, using an importer of the CAD model to GOTHIC is used to obtain the GOTHIC 3D model.

Control volumes (CVs) in GOTHIC are used to represent the regions occupied by a fluid. The full containment is represented in a single CV with dimensions of $45 \times 45 \times 80 \mathrm{~m}$ (Fig. 1). In GOTHIC, blockages can be defined within subdivided volumes to model objects that displace fluid within a volume or to model the volume shaped boundaries. It allows to model geometries that restrict the flow between cells of a subdivided volume. For this model, 534 blockages were needed to de fine the internal geometry of the UPM PWR containment building. The 


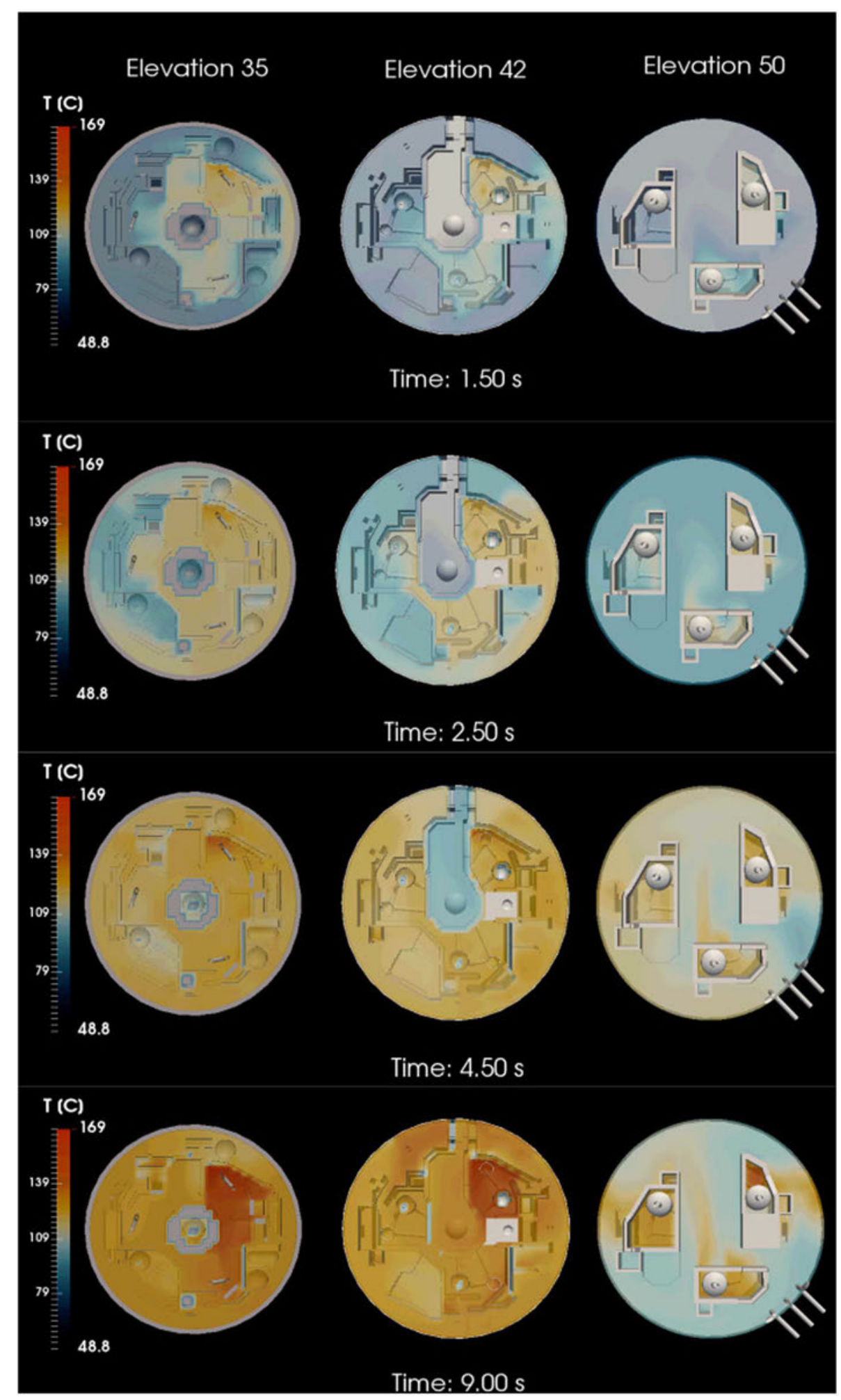

Fig. 11. Temperature evolution inside containment (base case). 


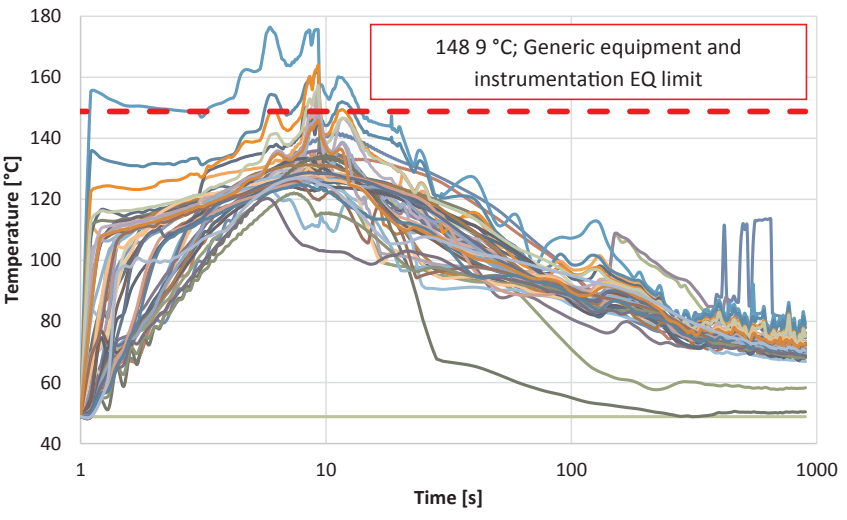

Fig. 12. Maximum room temperature of each room (base case).

The use of flow paths or 3D connectors to communicate fluid be tween different regions is unnecessary due to all apertures and complex structures are represented with blockages in the same CV.

Thermal Conductors (TCs) are used to model the heat capacity of solid structures, heat transfer between the fluid and these structures, heat transfer through solid structures separating volumes, and heat sources associated with the structures. To represent the thermal con nection in the 3D models, several TCs were used connecting thermally different regions separated by a wall, and also to model the con densation over the different surfaces, including the Steam Generators (SGs), the liner and the polar crane. Therefore, 262 spanned TCs were implemented in the model.

For convective heat transfer, the fluid temperature and the Heat Transfer Coefficient (HTC) are calculated using different correlations. For natural convection, the McAdams correlations (McAdams, 1954) are set for the different surface types (EPRI, 2014a). Forced convection is not accounted in this analysis.

The GOTHIC DLM FM condensation model was used for the internal structures. SGs, Reactor Cooling System (RCS) pipes and pumps internal surface temperatures were fixed to the internal temperature provided by the input code. The external containment wall temperature was fixed

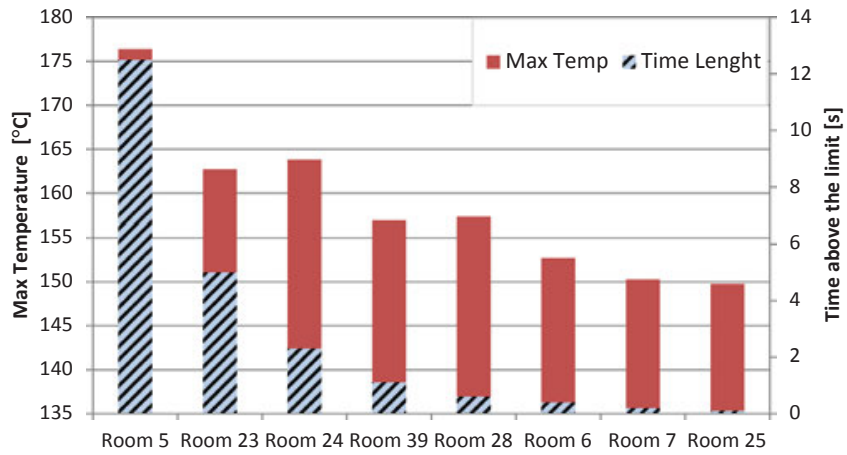

Fig. 14. Peak temperature and time above the generic limit inside several rooms (base case).

to $35{ }^{\circ} \mathrm{C}$ with a $\mathrm{HTC}$ of $11.35 \mathrm{~W} / \mathrm{m}^{2} \cdot{ }^{\circ} \mathrm{C}$ for the exterior convective heat transfer as seen in Ofstun and Scobel (2006).

\subsection{Mass \& energy release}

The postulated base case consist of a DEGB LOCA in the RCS cold leg, later a sensitivity analysis with respect to other RCS break locations is performed. The $\mathrm{M} \& \mathrm{E}$ release data, used as input, was obtained from a MELCOR model developed at UPM, and extensively used in different national and European projects, (Martin Fuertes et al., 1994; Ruiz Zapatero et al., 2016). As the containment model, the NPP taken as reference is a 3 Loop PWR W with a power generation of $2700 \mathrm{MW}_{\text {th }}$ and $900 \mathrm{MW}_{\mathrm{e}}$. For all the simulations, the accumulators, the high pressure injection and the low pressure injection are assumed available. Neither containment spray system nor containment HVAC cooling system are included in the simulation because the target variable of the simulations is the rooms peak temperature, and this occurs during the first seconds of the accident, during which the spray are not available due to the pumps delay start.

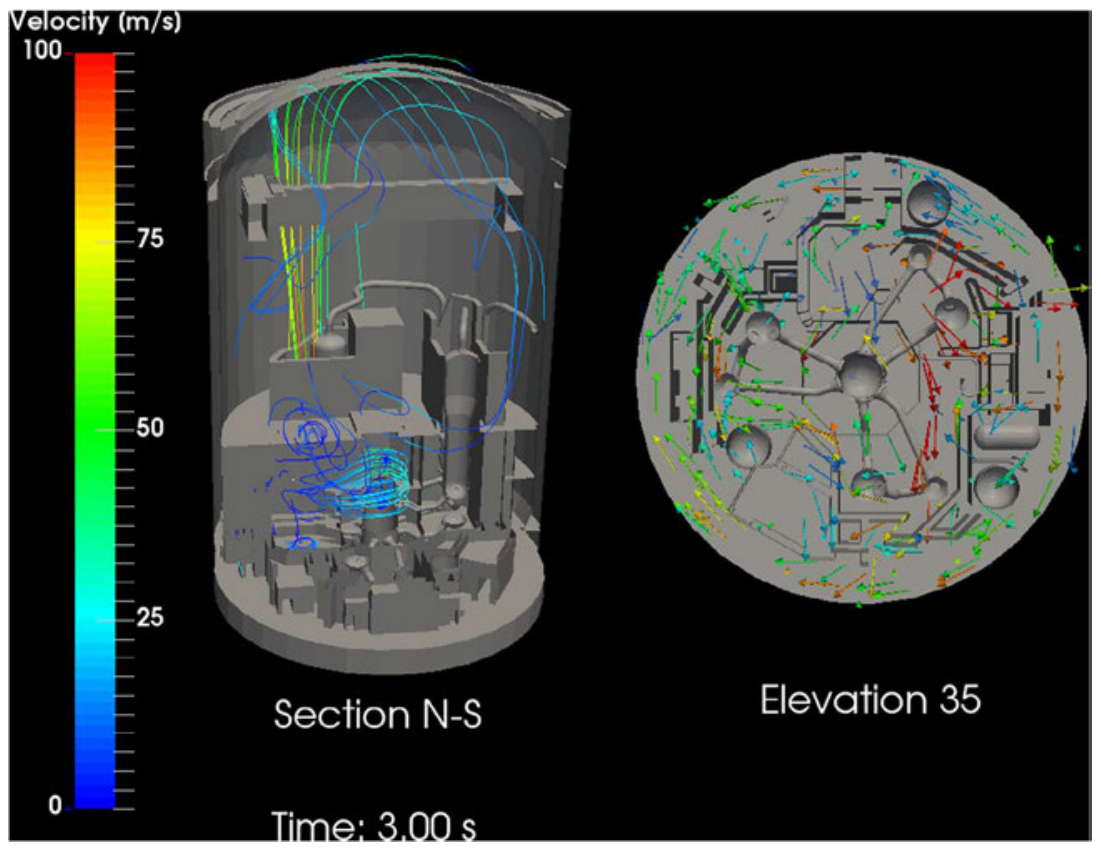

Fig. 13. Velocity vectors and streamlines at the beginning of the transient (base case). 
Table 2

Sensitivity cases.

\begin{tabular}{|c|c|c|c|c|c|c|c|c|c|}
\hline & Case 1 & Case 2 & Case 3 & Case 4 & Case 5 & Case 6 & Case 7 & Case 8 & Case 9 \\
\hline Loop & 1 & 2 & 3 & 1 & 2 & 3 & 1 & 2 & 3 \\
\hline Location & Cold leg & Cold leg & Cold leg & Hot leg & Hot leg & Hot leg & Pump Suction & Pump Suction & Pump Suction \\
\hline
\end{tabular}

Table 3

Max temperature sensitivity analysis results. Green color means that the generic limit $\left(148.9^{\circ} \mathrm{C}\right)$ has not been surpassed; Orange-Red means that the limit has been surpassed, the darker the color the higher the temperature.

\begin{tabular}{|c|c|c|c|c|c|c|c|c|c|}
\hline & 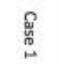 & 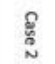 & 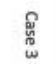 & 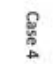 & 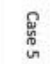 & 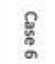 & 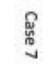 & 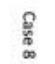 & ల్ \\
\hline oom 1 & 1.7 & 5.0 & 7.4 & 53.4 & 144.8 & 146.8 & 150.9 & 147.8 & 149.4 \\
\hline Room 2 & 133.1 & 132.2 & 129.4 & 141.6 & 127.8 & 131.0 & 139.2 & 150.2 & 130.9 \\
\hline Room 3 & 128.2 & 129.2 & 126.1 & 129.8 & 154.9 & 133.7 & 130.3 & 149.1 & 125.6 \\
\hline Room 4 & 128.4 & 128.9 & 124.3 & 129.6 & 156.8 & 132.1 & 130.6 & 145.3 & 125.1 \\
\hline Room 5 & 176.4 & 157.6 & 143.2 & 245.7 & 266.7 & 164.1 & 283.1 & 1510 & 146.5 \\
\hline Room 6 & 152.7 & 149.4 & 147.7 & 223.9 & 161.3 & 171.0 & 281.8 & 192.1 & 150.6 \\
\hline Room 7 & 150.3 & 213.2 & 163.5 & 183.6 & 228.8 & 196.8 & 253.9 & 255.8 & 160.1 \\
\hline Room 8 & 130.0 & 130.0 & 201.3 & 171.6 & 163.8 & 237.5 & 159.0 & 212.6 & 216.7 \\
\hline Room 9 & 139.8 & 138.4 & 147.4 & 174.2 & 151.9 & 163.1 & 144.0 & 207.1 & 150.7 \\
\hline Room 10 & 136.0 & 129.4 & 130.6 & 175.0 & 139.6 & 139.5 & 135.8 & 111.3 & 133.7 \\
\hline Room 11 & 128.9 & 129.4 & 131.6 & 1665 & 152.2 & 128.9 & 235.7 & 136.8 & 129.5 \\
\hline Room 12 & 128.7 & 128.4 & 123.8 & 169.1 & 170.9 & 125.6 & 132.9 & 158.0 & 128.1 \\
\hline Room 13 & 128.1 & 133.4 & 138.0 & 165.7 & 176.7 & 132.8 & 143.5 & 1512 & 135.9 \\
\hline Room 14 & 135.5 & 138.6 & 152.9 & 157.3 & 195.6 & 181.3 & 176.5 & 198.7 & 154.0 \\
\hline Room 15 & 48.8 & 48.8 & 48.8 & 3.8 & 18.8 & 48.8 & 48.8 & 48.8 & 48.8 \\
\hline Room 16 & 130.3 & 136.6 & 161.5 & 160.0 & 191.7 & 196.8 & 159.2 & 207.4 & 159.4 \\
\hline Room 17 & 128.0 & 131.8 & 127.3 & 141.1 & 181.1 & 157.5 & 140.8 & 115.5 & 129.1 \\
\hline Room 18 & 128.8 & 130.2 & 126.8 & 133.1 & 174.8 & 130.2 & 137.2 & 158.5 & 128.6 \\
\hline Room 19 & 128.2 & 131.0 & 128.8 & 130.1 & 177.2 & 168.8 & 138.8 & 177.6 & 129.4 \\
\hline Room 20 & 127.2 & 125.3 & 133.4 & 137.8 & 124.3 & 178.9 & 129.3 & 170.9 & 252.2 \\
\hline Room 21 & 130.1 & 130.5 & 105.6 & 128.1 & 128.0 & 107.8 & 129.6 & 136.3 & 108.3 \\
\hline Room 22 & 136,5 & 135.8 & 128.1 & 133.8 & 131.2 & 159.8 & 139.0 & 132.0 & 130.6 \\
\hline Room 23 & 162.7 & 141.6 & 152.4 & 231.8 & 200.0 & 218 & 172. & 19 ? & 163.7 \\
\hline Room 24 & 163.8 & 140.2 & 142.5 & 227.7 & 154.0 & 154.5 & 167.1 & 132.5 & 144.8 \\
\hline Room 25 & 9.8 & 0 & & .0 & .6 & 8.6 & 156.5 & 6 & 49.0 \\
\hline Room 26 & 134.4 & 129.2 & 157.4 & 133.0 & 140.0 & 182.2 & 163.0 & 193.4 & 154.8 \\
\hline Room 27 & 131.4 & 127.1 & 5 & 0 & 139.1 & 205.3 & 154.4 & 74.3 & 163.5 \\
\hline Room 28 & 157.3 & 37.5 & 143.2 & 145.2 & 45,0 & 143 & 149 & 1615 & 145.6 \\
\hline Room 29 & 128.5 & 128.1 & 129.7 & 159.4 & 136.7 & 136.4 & 131.7 & 133.9 & 132.3 \\
\hline Room 30 & 128.7 & 128.6 & 3 & 4 & & 127.6 & 8 & 4 & 29.4 \\
\hline Room 31 & 133.4 & 129.1 & 132.6 & 164.9 & 133.5 & 132.4 & 129.6 & 139.0 & 135.7 \\
\hline Room 32 & 130.1 & 131.7 & 38.6 & 129.0 & 159.4 & 15 & 158.5 & 158.6 & 140.0 \\
\hline Room 33 & 134.8 & 138.8 & 36.7 & 140.7 & 50.3 & 137.1 & 138.6 & 136.0 & 139.2 \\
\hline Room 34 & 124.4 & 121.4 & 128.8 & 127.5 & 122.2 & 140.4 & 128.7 & 141.0 & 128.5 \\
\hline Room 35 & 126.1 & 23.5 & & 4 & & & 1.2 & 16.2 & 29.4 \\
\hline Room 36 & 131.3 & 1 & 1 & 4 & 166.6 & 3 & 133.6 & 10 & 127 \\
\hline Room 37 & 126.8 & 128.5 & 127.9 & 128.3 & 1587 & 146.6 & 129.6 & 106.2 & 129 \\
\hline Room 38 & 127.8 & 13 & 132.2 & 1 & 123.1 & 168. & 3 & & 48.0 \\
\hline Room 39 & 157.0 & 1 & 3 & 189.0 & 148.6 & 200.1 & 157.7 & 0.1 & 152.2 \\
\hline Room 40 & 148.1 & 132.6 & 139.8 & 187.4 & 148.2 & 144.1 & 144.0 & 130.0 & 141.7 \\
\hline Room 41 & 124.1 & 129.1 & 140.4 & 167.4 & 140.2 & 158.9 & 120.1 & 31.0 & 44.7 \\
\hline Room 42 & 130.2 & 123.4 & 143.7 & 181.6 & 120.7 & 163.5 & 154.3 & 274.0 & 146.5 \\
\hline Room 43 & 128.7 & 126.5 & 140 & 165.6 & 13 & 16 & 137. & & 138.7 \\
\hline Room 44 & 126.1 & 226.8 & 128.1 & 180.8 & 4 & 127.5 & 127.4 & 28.0 & 128.5 \\
\hline Room 45 & 122.1 & 120.5 & 127.8 & 124.8 & 124.8 & & 4.6 & .0 & 31.2 \\
\hline Room 46 & 120.3 & 117.1 & 130.3 & 119.6 & 116.3 & 129.0 & 120.4 & 121.0 & 133.6 \\
\hline Room 47 & 124.7 & 11 & 12 & 12 & 4 & & 7 & 1 & 39.9 \\
\hline Room 48 & 145.9 & 134.0 & 139.2 & 194.6 & 15 & 258.4 & 151.6 & 152.3 & 140.9 \\
\hline Room 4 & 127.1 & 123 & 119.8 & 156.6 & 123.1 & 126.5 & 131.0 & 134.6 & 12 \\
\hline
\end{tabular}

\subsection{Post processing}

To process the GOTHIC output files, the ProTON code (Fernández Cosials, 2017), developed in the UPM Nuclear Safety Group, was used. The goal of ProTON is to obtain the average temperature and pressure distribution over each compartment due to GOTHIC 8.1 does not allow to do it directly. ProTON is also used to obtain wall temperatures, heat fluxes and condensed masses.
For qualitative results, the ParaView (Utkarsh Ayachit, 2015) post processor is used. These results are useful for a rapid understanding of the temperature distribution over the different compartments to locate the local damage produced.

To perform the local damage analysis, 49 compartment zones have been defined as shown in Figures in the Annex A, (Figs. 15 17). Room 49, which is not represented in the Figures shown in the Annex A, correspond to the dome region. The layouts shown in this annex are a reconstruction made from Martin Fuertes et al. (1994).

\section{Simulation results}

The main objective of the present simulation is to obtain informa tion about temperatures inside the different rooms of the containment. Firstly, a base case will be explained in detail, and afterwards, the re maining cases will be summarized. The base case, sensitivities, and M \& E release input are all performed under the BE approach, avoiding conservative hypothesis.

\subsection{Base case results}

As commented above, the transient simulated will be a DEGB LOCA located in the cold leg of the Loop 1. The M \& E release is modeled with four boundary conditions, one for each side of the break, and one for each phase (liquid and vapor). For each $\mathrm{M} \& \mathrm{E}$ release there are three sets of data: mass flow, temperature and pressure. The $\mathrm{M} \& \mathrm{E}$ release input for the liquid of the vessel side break can be observed in Figs. 26. On this figures, a high peak of mass flow is observed the first seconds after the break. After the initial peak, the flow is slowly getting lower as the pressure inside the primary system is decreasing. The liquid com ponent of the break enters the containment in a superheated state, provoking an instant break up into small drops and then a sudden va porization. When the temperature and pressure decreases, the liquid flow enters the containments without vaporization.

The simulation time is set to $1000 \mathrm{~s}$; the break occurs at the first second. The calculation time was approximately $95 \mathrm{~h}$ using 5 cores (Intel i5 $3.2 \mathrm{GHz}$ ). The results were post processed with the tools before mentioned, ProTON and ParaView. The average pressure and tem perature can be seen in Figs. 7 and 8 .

The averaged values are calculated taking into account the volume of each cell and its net porosity. The pressure reaches its peak of $260 \mathrm{kPa}$ at $11 \mathrm{~s}$, while the average temperature peak reaches $114^{\circ} \mathrm{C}$. These values are both under the limits stipulated by the classical maximum Pressure and Temperature (PT) criteria $\left(148.9^{\circ} \mathrm{C}\right.$ and $448 \mathrm{kPa}$ ). After the initial peak, the containment structures and the concrete walls behave as a heat sink lowering the containment pressure and temperature. At $1000 \mathrm{~s}$, the pressure and temperature have de creased to half of their maximum values.

This behavior is analogous to similar LBLOCA analyses in a PWR W containment found in the literature, (Beeny et al., 2016). An initial rapid peak followed by a slow descent in pressure and temperature caused by condensation and convection with the heat sinks.

When the average temperature and pressure of each room is ob served, the following curves are obtained (Figs. 9 and 10). Each line corresponds to every room analyzed, and the red dotted line is the temperature limit imposed for a generic PWR in IEEE (1974).

Taking into account the individual room information, the develop ment of the transient varies widely in some cases. At the beginning of 
the transient, the pressure is nearly homogeneous in all rooms except for those close to the break that are pressurized slightly before the others. There is another non homogeneous pressurization in three rooms: the refueling pool, with its lower zone, and the drain pump room, whose pressurization is slower or non existent because they are assumed to be, completely or partially, airtight. At the end of the transient, the differences in pressure in some rooms are provoked by the condensed water, which is accumulated in certain rooms and adds extra pressure because of the water column. The pressure stays under the limits globally and also locally during the whole transient. The pressure differences could represent a challenge to the structural integrity and are been analyzed by the UPM with finite element models.

Regarding the temperature evolution, it does not reach homo geneity at any moment. Even though all room temperature evolutions have similar structure (initial peak followed by a slow descent), the temperature transport, as it was previously explained, is mostly a convective diffusive process, and its spreading is much slower than pressure, see Fig. 11. This originates that nearly all rooms have different temperatures, and that these high temperature peaks do not lower quickly as can be seen in Fig. 9.

Maximum temperatures reached are shown in Fig. 12. The hot spot appears in Room 5, where the break is located and then this high temperature vapor is transported to the adjacent rooms, as well as to the dome (Room 49). The vapor moves through the SG1 enclosure (Room 5), as shown in the streamlines, Fig. 13.

In certain rooms, this peaks exceed the EQ temperature limits. This is summarized in Fig. 14. In this graph, the maximum temperature reached by any of the room cells is displayed in red. In addition, the time that the room is exceeding the temperature limit is displayed in blue. It can be seen that room 5 , which is the room where the break is located, the maximum temperature inside reaches $176.41{ }^{\circ} \mathrm{C}$ at some point of the transient. The time that room 5 exceeds the limits is the longest. However, it only surpasses the limits during the blowdown phase. Even though the $\mathrm{M} \& \mathrm{E}$ release continues releasing the primary inventory and also water from the Accumulators (ACC), Low Pressure Safety Injection (LPSI) and High Pressure Safety Injection (HPSI), this high temperatures are not reached again.

Under the generic temperature limit $\left(148.9^{\circ} \mathrm{C}\right)$, this $\mathrm{BE}$ simulation would exceed the generic equipment qualifying limit in 8 rooms. Excluding these 8 rooms, the remaining ones are all under the limits during the whole transient.

\subsection{Sensitivity analysis}

Taking into account that the containment conditions evolution and the local damage produced is highly dependent on the break location and the corresponding $\mathrm{M} \& \mathrm{E}$ release input, eight sensitivity cases were performed, Table 2. Case 1 corresponds to a the Base Case, analyzed before.

For each case, the $\mathrm{M} \& \mathrm{E}$ release data was extracted from the cor responding MELCOR simulation, and implemented in GOTHIC after wards. All cases were analyzed with ProTON and the summary of the results can be seen in Table 3 .

It is found that in every simulation the EQ limits are exceeded in at least one room inside the containment in all simulations. Damage times and maximum temperatures vary between simulations. However, it is possible to observe that hot leg break simulations leads to higher temperatures and damage times, and therefore local damage in these simulations is higher.

The in containment generic equipment EQ limits, as well as the operating range of the containment instrumentation are clearly reached, and therefore its function can be impaired. Even if a higher limit is used to assess the criteria, such as the temperature range showed in Table 1, some simulations performed widely surpass those limits.

\section{Conclusions}

Containment analyses have been usually performed using LP ap proach, given that the containment conditions during a DBE are ex treme in terms of pressure or temperature gradients, $\mathrm{M} \& \mathrm{E}$ release and that the usual containment volume is around $60,000 \mathrm{~m}^{3}$. Three di mensional codes have been normally used for containment analysis in terms of hydrogen risk analysis. Previous research at UPM used a three dimensional model for a pressure and temperature analysis and has shown that containment lumped analysis are correct in terms of pres sure, but can hide high temperature peaks.

Containment equipment and instrumentation are qualified based on pressure and temperature enveloping profiles, normally calculated with LP models. However, this containment temperature obtained with LP models is an average value and does not correctly represent the het erogeneity of this parameter.

Exploring this argument, a generic equipment and instrumentation EQ limit criterion, based on the most commonly used limit during the last decades, has been used in this work. To compare against the limits, the maximum temperature of this profile is taken $\left(148.9^{\circ} \mathrm{C}\right.$ with an $8{ }^{\circ} \mathrm{C}$ margin) because if this temperature is exceeded anytime during the transient, the EQ criteria will be surely surpassed. Subsequently, these limits has been used to assess a DEGB LOCA in a PWR W 3D contain ment model developed with GOTHIC 8.1 (QA); showing that in all sensitivity cases analyzed, at least in one room, the EQ limit is sur passed. If the temperatures obtained from the different simulations are compared against plant specific higher EQ limits, there are still several rooms in which those limits are surpassed.

From the results obtained, a proposal is raised: 3D models should be used to evaluate the potential damage for the containment equipment and instrumentation during an accident. The EQ basis for equipment and instrumentation should be made taking into account the results from 3D detailed models, because the temperature heterogeneity in the containment rooms makes invalid the average values of LP models.

Evaluating the results, it is not perfectly clear which sequence is the most severe, in terms of temperature limits, as only a LBLOCA is si mulated. To create an enveloping EQ criteria, it is proposed to develop a methodology that takes into account not only the HELB break size, but also the location and the orientation.

With the industry trends on CFD use, it is maybe time to reconsider the way the methodology of temperature and pressure enveloping profiles for EQ equipment and instrumentation is being performed.

\section{Acknowledgments}

This work has been funded by the Spanish Ministry of Competitiveness and Economy within PYGAS project: ENE2015 67638 $\mathrm{R}$ (MINECO/FEDER). Its support is gratefully acknowledged.

The author acknowledges the computer resources and technical assistance provided by the Centro de Supercomputación y Visualización de Madrid (CesviMa).

The authors want to express their deep gratitude to EPRI and NAI company personnel, especially Tom George and Nate Carstens, for their valuable technical support and help during the development this work. 


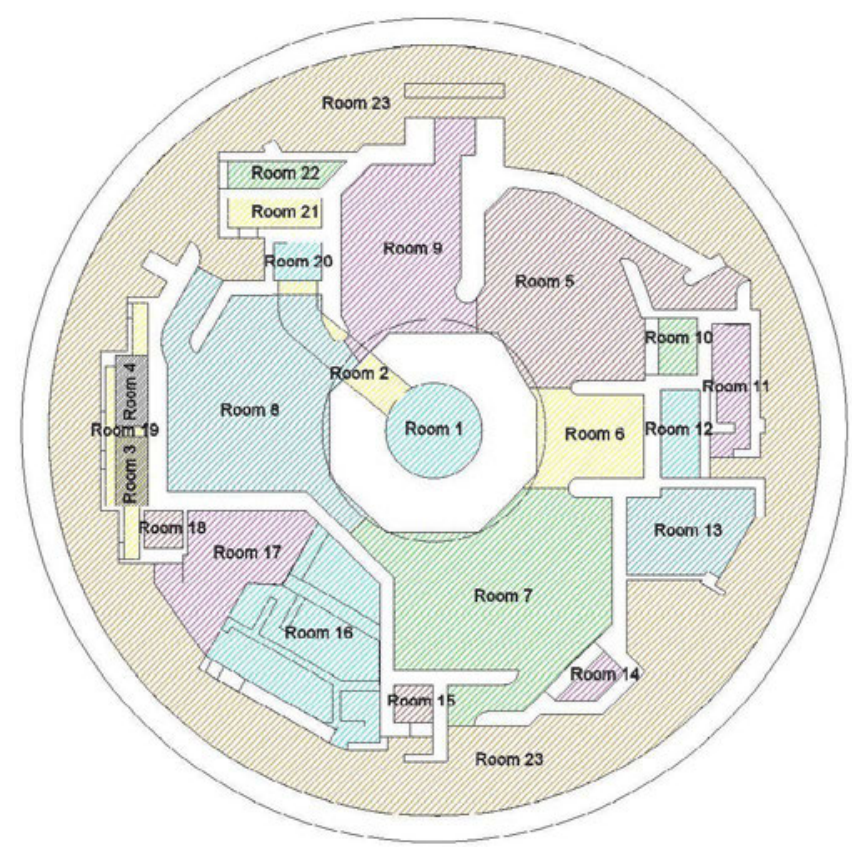

Fig. 15. PWR Analyzed Zones, lower elevation. Adapted from Martin-Fuertes et al. (1994).

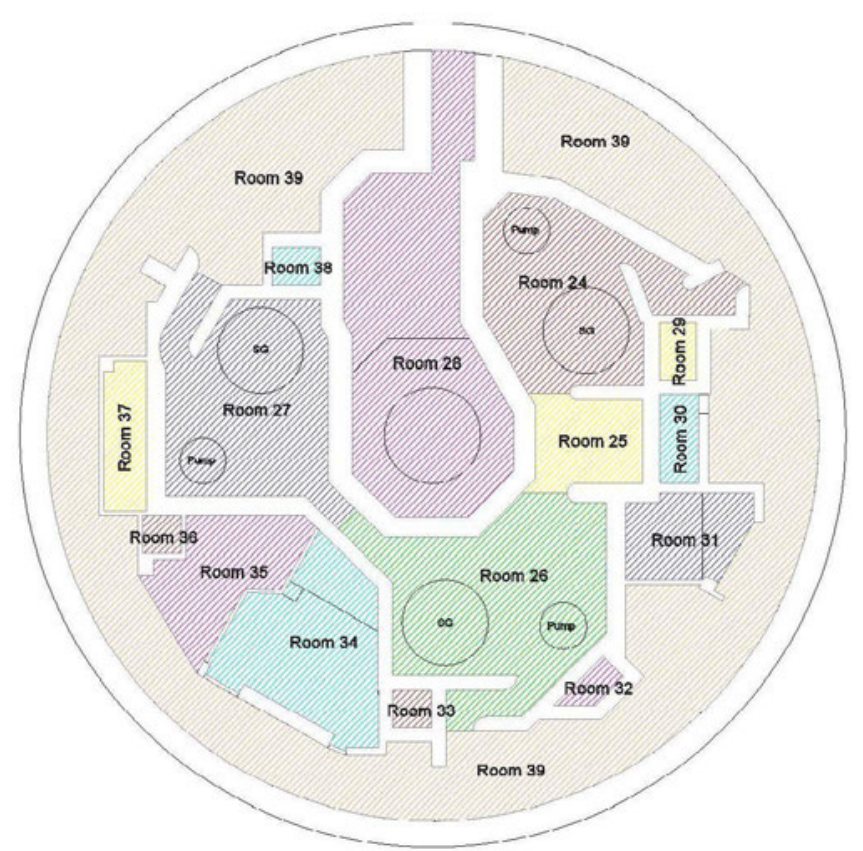

Fig. 16. PWR Analyzed Zones, middle elevation. Adapted from Martin-Fuertes et al. (1994). 


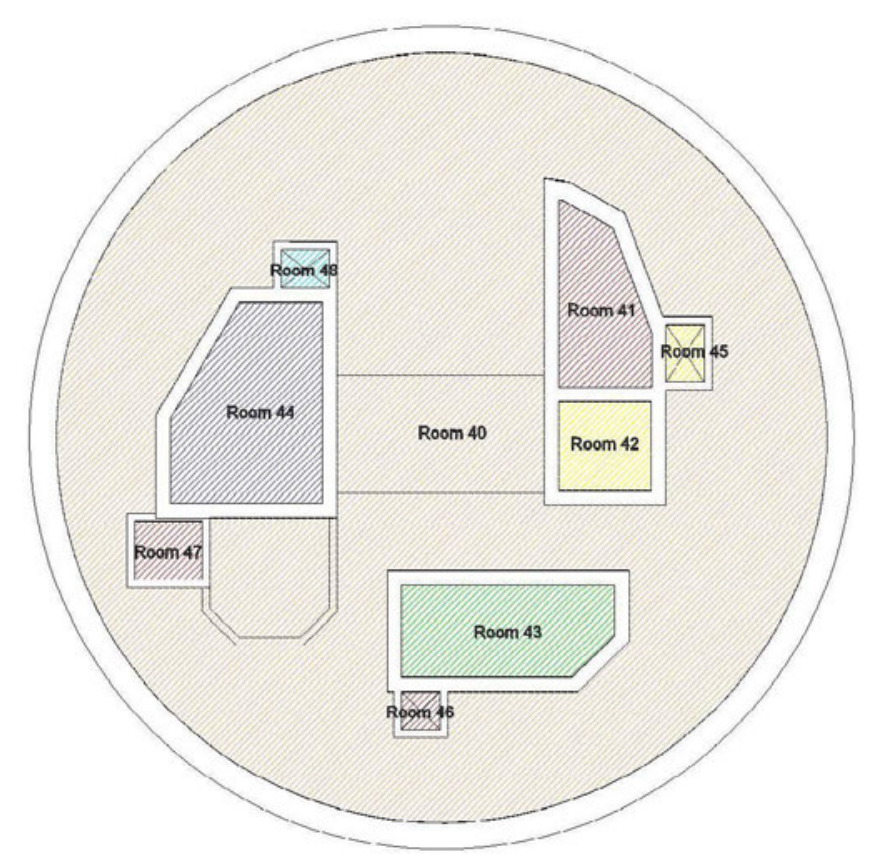

Fig. 17. PWR Analyzed Zones, higher elevation. Adapted from Martin-Fuertes et al. (1994).

\section{References}

Abdelghany, J.M., Guimond, P.J., Higar, K.E., Wissinger, G.J., 2004. Analysis of Containment Response to Postulated Pipe Ruptures Using GOTHIC. BAW-10252(NP) Revision 0.

Abou-Rjeily, Y., Cénérino, G., Drozd, A., Lee, S., Misak, J., Park, C.O., Preusser, G., Vayssier, G.L.C.M., 2011. Mitigation of Hydrogen Hazards in Severe Accidents in Nuclear Power Plants, Iaea-Tecdoc-1661.

Andreani, M., Paladino, D., George, T., 2010. Simulation of basic gas mixing tests with condensation in the PANDA facility using the GOTHIC code. Nucl. Eng. Des. 240, 1528-1547. http://dx.doi.org/10.1016/j.nucengdes.2010.02.021.

Arcieri, W.C., Hanson, D.J., 1991. Instrumentation Availability for a Pressurized Water Reactor With a Large Dry Containment During Severe Accidents. NUREG/CR-5691.

Basic, I., 2015. Instrumentation to mitigate severe accidents. In: IAEA Training Workshop on Severe Accident Management Guideline. Vienna.

Beeny, B., Vaghetto, R., Vierow, K., Hassan, Y.A., 2016. MELCOR and GOTHIC analyses of a large dry pressurized water reactor containment to support resolution of GSI-191. Nucl. Technol. 196, 292-302. http://dx.doi.org/10.13182/NT16-36.

Bocanegra, R., Jimenez, G., Fernández-Cosials, M.K., 2016. Development of a PWR-W GOTHIC 3D model for containment accident analysis. Ann. Nucl. Energy 87, 547-560. http://dx.doi.org/10.1016/j.anucene.2015.10.022.

Cavlina, N., Feretic, D., Grgic, D., Spalj, S., Spiler, J., 1996. Use of GOTHIC code for assessment of equipment environmental qualification. In: International Conference Nuclear Option in Countries with Small and Medium Electricity Grids, pp. 227-234.

Clark, A., Fröding, R., 2014. Combining multiple design basis test specifications into a single enveloping test. In: 26th Annual EQ Technical Meeting. Clearwater Beach, FL.

Corradini, L.M., 1984. Turbulent condensation on a cold wall in the presence of a noncondensable gas. Nucl. Technol. 64, 186-195.

Dominion, 2006. Gothic Methodology for Analyzing the Response to Postulated Pipe Ruptures Inside Containment. DOM-NAF-3-NP-A.

Duke Power Company, 2004. Mass and Energy Release and Containment Response methodology, DPC-NE-3003-A.

EPRI, 2010. Plant Support Engineering: Nuclear Power Plant Equipment Qualification Reference Manual, Revision 1. 1021067.

EPRI, 2014a. GOTHIC Thermal Hydraulic Analysis Package, Version 8.1 (QA). Palo Alto, CA.

EPRI, 2014b. Gothic Thermal Hydraulic Analysis Package Version 8.1 (QA). Palo Alto, CA.

European Commission, 1996. A Comparison of European Practices for the Qualification of Electrical and I \& C Equipment Important to Safety for European LWR Nuclear Power Plant. EUR 16246.

Fernández-Cosials, K., 2017. Analysis and Improvement of Hydrogen Mitigation Strategies During a Severe Accident in Nuclear Containments. Universidad Politécnica de Madrid.

Fernández-Cosials, M.K., Jimenez, G., Lopez-Alonso, E., 2016. Analysis of a gas stratification break-up by a vertical jet using the GOTHIC code. Nucl. Eng. Des. 297, 123-135. http://dx.doi.org/10.1016/j.nucengdes.2015.11.035.

Hashemian, H., 2006. Maintenance of Process Instrumentation in Nuclear Power Plants. Springer Science + Business Media, Berlin.

Hessheimer, M.F., Dameron, R.A., 2006. Containment Integrity Research at Sandia
National Laboratories: An Overview, NUREG/CR-6906.

Hyun, K., Sup, C., Soo, D., 2006. Thermal Analysis for Environmental Qualification of Kori Nuclear power plant unit 3 and 4. In: Transactions of the Korean Nuclear Society Autumn Meeting 1-2.

IEEE, 1974. IEEE Standard for Qualifying Class 1E Equipment for Nuclear Power Generating Stations. IEEE std 323-1974. doi:10.1109/IEEESTD.1974.6568022

IEEE, 2003. IEEE Standard for Qualifying Class 1E Equipment for Nuclear Power Generating Stations. IEEE Std 323-2003. doi: 10.1109/IEEESTD.2004.94415.

IEEE, 2016. Nuclear facilities - Electrical equipment important to safety - Qualification, IEC/IEEE 60780-323:2016.

Jiménez, G., Bocanegra, R., Fernández-Cosials, K., Queral, C., Montero-Mayorga, J., 2014. Development of a PWR-W and an AP1000 containment building 3D model with a CFD code for best-estimate thermal-hydraulic analysis. In: ICONE22. ASME, Prague, pp. 6. http://dx.doi.org/10.1115/ICONE22-30445.

Jimenez, G., Serrano, C., Lopez-Alonso, E., del Molina, M., Calvo, D., García,, J., Queral, C., Zuriaga, J.V., González, M., 2015. BWR Mark III containment analyses using a GOTHIC 8.0 3D model. Ann. Nucl. Energy 85, 687-703. http://dx.doi.org/10.1016/j. anucene.2015.06.025.

Kim, J., Hong, S.-W., Kim, S.-B., Kim, H.D., Lee, U., Royl, P., Travis, J.R., 2004. 3Dimensional analysis of the steam-hydrogen behavior from a small brak loss of coolant accident in the APR1400 containment. J. Korean Nucl. Soc. 36, 24-35.

King, D.B., Nicolette, V.F., Dandini, V.J., Spletzer, B.L., 1988. Safety-Related Equipment Survival in Hydrogen Burns in Large Dry PWR Containment Buildings. NUREG/CR4763 SAND86-228.

Knudson, D.L., Rempe, J.L., Lutz, R.J., 2015. Scoping Study Investigating PWR Instrumentation during a Severe Accident Scenario.

Martin-Fuertes, F., Fernandez, J.A., Aleza, S., Máz, I., Lopez, J.V., Sánchez, J., Alonso, A., 1994. Analysis of Three Severe Accident Sequences (AB, SGTR and V) in a 3 Loop WPWR 900 MWe NPP with the MELCOR code. European Commission EUR 16054.

Martín-Valdepeñas, J.M., Jiménez, M.a., Martín-Fuertes, F., Fernández, J.A., 2007. Improvements in a CFD code for analysis of hydrogen behaviour within containments. Nucl. Eng. Des. 237, 627-647. http://dx.doi.org/10.1016/j.nucengdes.2006. 09.002 .

McAdams, W.H., 1954. Natural convection. In: W-Hill, M. (Ed.), Heat Transmission. United States of America, pp. 165-183.

MHI, 2013. US-APWR Equipment Qualification Program MUAP-08015.

NRC, 1981. Interim Staff Position on Environmental Qualification of Safety-Related Electrical Equipment. NUREG-0588.

NRC, 1983. CFR 10 Part 50.49 Environmental Qualification of Electrical Equipment Important to Safety for Nuclear Power Plants. Code of Federal Regulations.

NRC, 1984. Environmental Qualification of Certain Electric Equipment Important to Safety for Nuclear Power Plants. Regulatory Guide 1.89 Revision 1.

NRC, 1988. Compendium of ECCS Research for Realistic LOCA Analysis. NUREG-1230. NRC, 2015. Appendix A to Part 50-General Design Criteria for Nuclear Power Plants.

OECD/NEA, 2014a. Best Practice Guidelines for the Use of CFD in Nuclear Reactor Safety Applications. Nea/Csni/R(2014) 11.

OECD/NEA, 2014b. Assessment of CFD Codes for Nuclear Reactor Safety Problems. Nea/ Csni/R(2014) 12

OECD/NEA, 2014c. NEA/CSNI/R(2014) 8. Status Report on Hydrogen Management and Related Computer Codes.

Ofstun, R., 2001. Development and Qualification of a GOTHIC Containment Evaluation 
Model for the Kewaunee Nuclear Power Plant. WCAP-15667.

Ofstun, R., 2004. Development and Qualification of a GOTHIC Containment Evaluation Model for the Prairie Island Nuclear Generating Plants. WCAP-16219-NP Westinghou.

Ofstun, R., Scobel, J., 2006. Westinghouse Containment Analysis Methodology. WCAP16608-NP 1-164.

Paladino, D., Zboray, R., Benz, P., Andreani, M., 2010. Three-gas mixture plume inducing mixing and stratification in a multi-compartment containment. Nucl. Eng. Des. 240, 210-220. http://dx.doi.org/10.1016/j.nucengdes.2008.07.014.

Royl, P., Rochholz, H., Breitung, W., Travis, J., Necker, G., 2000. Analysis of steam and hydrogen distributions with PAR mitigation in NPP containments. Nucl. Eng. Des. 202, 231-248. http://dx.doi.org/10.1016/S0029-5493(00)00332-0.

Ruiz-Zapatero, M., Bocanegra, R., Jiménez, G., Queral, C., 2016. Modelo detallado para un diseño estandar PWR-W con el codigo MELCOR 2.1. In: 42th Annual Meeting of Spanish Nuclear Society. Santander, Spain.

Sehgal, B.R., 2012. Nuclear Safety in Light Water Reactors - Severe Accident
Phenomenology. Academic Press.

Tills, J., Notafrancesco, A., Phillips, J., 2009. Application of the MELCOR Code to Design Basis PWR Large Dry Containment Analysis, SAND2009-2858. doi: SAND2009-2858.

Travis, J.R., Jordan, T., Royl, P., Benz, S., Xiao, J., Xu, Z., 2011. GASFLOW User's Manual. Karlsruhe.

Utkarsh Ayachit, 2015. The Paraview Guide. Kitware Inc.

WEC, 2004. Development and Qualification of a GOTHIC Containment Evaluation Mode for the Prairie Island Nuclear Generating Plants g Containment Evaluation Model for the. WCAP-16219-NP.

WEC, 2013. Westinghouse Containment Analysis Methodology - PWR LOCA Mass and Energy Release Calculation Methodology. WCAP-17721-NP.

Whitley, R.H., Chan, C.K., Okrent, D., 1976. On the analysis of containment heat transfer following a LOCA. Ann. Nucl. Eng. 3, 515-525.

Wolf, L., Holzbauer, H., Schall, M., Con-, K.B.M., 1999. Comparisons between lumpedparameter gothic containment analyses with data. Nucl. Technol. 125, 155-165. 